\title{
The Awareness of cultural orientations in culturally responsive education for Korean American students
}

\author{
Mi-Soon Lee \\ University of Connecticut
}

Follow this and additional works at: https://digitalscholarship.unlv.edu/jpme

\section{Repository Citation}

Lee, Mi-Soon (2007) "The Awareness of cultural orientations in culturally responsive education for Korean American students," Journal of Praxis in Multicultural Education: Vol. 2: No. 1, Article 3.

DOI: 10.9741/2161-2978.1022

Available at: https://digitalscholarship.unlv.edu/jpme/vol2/iss1/3

This Article is protected by copyright and/or related rights. It has been brought to you by Digital Scholarship@UNLV with permission from the rights-holder(s). You are free to use this Article in any way that is permitted by the copyright and related rights legislation that applies to your use. For other uses you need to obtain permission from the rights-holder(s) directly, unless additional rights are indicated by a Creative Commons license in the record and/ or on the work itself.

This Article has been accepted for inclusion in Journal of Praxis in Multicultural Education by an authorized administrator of Digital Scholarship@UNLV. For more information, please contact digitalscholarship@unlv.edu. 


\title{
The Awareness of Cultural Orientations in Culturally Responsive Education for Korean American Students
}

\begin{abstract}
Mi-Soon Lee
It is important for teachers to be aware of the cultural backgrounds of students and their family in order to provide culturally responsive instruction and counseling. Most teachers may identify Asian ethnicities due to their distinguishable physical or behavioral characteristics but they may not know how Asian Americans have changed their cultural value and legacies. To examine cultural orientation, the Korean American Acculturation Scale $(K A A S)$, which consists of behavior and cultural value orientations, was administered to 466 Korean American students. The result indicated that the most recent generations were less behaviorally oriented to Korean culture and more disoriented to Korean cultural value after controlling the affect of age. However, the degree of behavior and cultural value disorientation to Korean culture varied among individual Korean American students, depending on their genders and/or generations. Korean American students seemed to choose the degree and mode of their cultural orientation selectively during their acculturation.
\end{abstract}

The school context has become increasingly diverse as different ethnic students bring their varied cultural and historical experiences into the United States (Cheng, Ima, \& Labovitz, 1994; Lynch \& Hanson, 1998; Park \& Chi, 1999). By 2020, approximately $45.5 \%$ of school-age children will be young people of color (Banks, 1993), who have meaningfully different needs from other students.

Two educational perspectives for the characteristics and needs of culturally diverse students exist: cultural deficit and cultural differences. The deficit perspective reflects a value system that holds the mainstream culture as the norm, where deviations are viewed as inferior. Since cultural values of the mainstream group may have an impact on what is recognized as worthy or who is regarded as talented, educators with this perspective could force students from

Mi-Soon Lee, Ph.D., graduated from the University of Connecticut in Educational Psychology with a concentration on Gifted and Talented Education. Her areas of interest are in the field of gifted education (creativity development), multicultural education (Asian Americans), and early childhood education (attachment, socio-emotional behavior, and attribution theory). She is interested in curriculum development that supports teachers who work with highly able students. 
different cultures to relinquish their cultural roots and become "mainstreamed." So, students could face internal conflict and face confusion between loyalty to the cultural traditions of their heritage and the pressure for conformity to the mainstream society (VanTassel-Baska, Olszewski-Kubilius, \& Kulieke, 1994).

During the 1980s, the idea of cultural differences became common and, in some ways, replaced the cultural deficit perspective. This belief holds that students reared in different environments will necessarily be different and different cultures exist as parallel or co-cultures (Ford, Howard, Harris, \& Tyson, 2000). Unlike the cultural deficit perspective, the cultural differences perspective focuses on how teachers and other school personnel interpret the behaviors and performances of culturally diverse students (Shade, Kelly, \& Oberg, 1997).

In relating these perspectives to characteristics of culture, it is important to mention that culture changes and is not static. As a culturally diverse group usually interacts with the mainstream culture, cultural modes and values slowly evolve (Gollnick \& Chinn, 1994, cited in Mau, 1998). Individuals vary greatly in their abilities to function within new cultural environments (LaFromboise, Coleman, \& Gerton, 1993) and may seek different levels of attachment to and involvement in the mainstream culture and their culture of origin (Padilla, 1980). That is, individuals adapt to the culture of the mainstream by incorporating selected behaviors and values (Dasgupta, 1989; Nguyen \& Peterson, 1993; Nguyen \& Williams, 1989). The degree or styles of cultural adaptation (acculturation) vary among individuals, depending on sociocultural and demographic variables such as ethnicity, religion, gender, age, generational status, years of residence in the mainstream culture, occupation, education, income, voluntary immigration versus involuntary immigration reasons, age at entry into the mainstream culture, geographic location, ethnic density of neighborhood, rural versus urban residence, family structure, and family size (Garcia \& Lega, 1979; Mercer, 1976; Sodowsky \& Carey, 1988; Sodowsky \& Plake, in press; Szapocznik \& Kurtines, 1980).

Tsai and his colleagues (Tsai, Ying, \& Lee, 2000) found that the relationship between being American and being Chinese was influenced by age of immigration more than length of time spent in the United States. Chinese Americans who immigrated to the United States during childhood (under 12 years old) were more susceptive to adopting an American identity.

Cultural adaptation has also been found to increase significantly with generational status (Padilla, 1980; Padilla, Lindholm, \& Wagatsuma, 1985). Likewise, ethnicity is generally believed to decrease over time, particularly from one generation to the next, as individuals become more assimilated into the mainstream society.

Gender influences both the process of acculturation and the extent to which cultural conflicts are experienced (Tang \& Dion, 1999). Brandon (1991) 
proposed that Chinese males adapted less easily to some aspects of North American culture than Chinese females. In contrast, some studies showed significantly higher acculturation scores for males than females, after controlling for education and employment (Bosher, 1995; Szapocznik, Scopetta, Kurtines, \& Arandale, 1978) and others showing no significant difference (Sodowsky, Lai, \& Plake, 1991). Thus, these suggest that age, generational status, and gender could be important personal factors in determining the degrees of cultural experience and conflicts perceived by culturally diverse students undergoing acculturation.

Researchers have developed a number of instruments to assess diverse ethnic group acculturation to the culture of the mainstream. A major criticism of most scales of acculturation is that they only measure the behavioral aspects of acculturation (e.g., food preference, friendship patterns, and language usage) and neglect to assess value acculturation (Betancourt \& Lopez, 1993; Cuéllar, Arnold, \& Maldonado, 1995; Leong, Wagner, \& Tata, 1995; Marin, Sabogal, Marin, Otero-Sabogal, \& Perez-Stable, 1987; Szapocznik, Kurtines, \& Fernandez, 1980).

The reason to consider values is that values are beliefs experienced as standards that individuals use to judge themselves and others. Cultural values held by cultural, ethnic, or racial groups include clusters of beliefs that shape all aspects of their functioning, including their family structures, traditions, interand intra-personal relationships, communication patterns, child rearing practices, and their perspective on the teaching/learning process.

According to Szapocznik and his colleagues (Szapocznik \& Kurtines, 1980; Szapocznik et al., 1978), the behavior acculturation process occurs more rapidly than the value acculturation process. The behaviors are needed to survive economically within the mainstream society, but there is no such equally compelling reason to adopt the mainstream group's values. With regard to Asian Americans, Sodowsky, Kwan, and Pannu (1995) found that Asian Americans might quickly adopt the behaviors of the United States culture, while maintaining their Asian cultural values.

In previous studies, many Asian American research participants were grouped together for analysis. They were not separated as Chinese, Korean, Japanese, and Vietnamese, although each group has encountered different adjustment problems because of its unique immigration pattern to the United States. As a result, past researchers overlooked the differences within and across Asian American subgroups (Suinn, Khoo, \& Ahuna, 1995). Korean Americans have distinctive cultural and developmental experiences in the United States. Some Korean Americans lack fluency in both Korean and English languages. Others might recognize the importance of Korean identity, but express feelings of ambiguity between being American and being Korean. 
Korean Americans tend to express themselves indirectly and speak softly and slowly. They expect others to be similarly sensitive and don't observe nonverbal messages well. Korean Americans unconsciously favor verbal hesitancy and ambiguity to avoid being offensive (Park, 1999), and they refrain from making spontaneous or critical remarks. Their body language is characterized by repeated head nodding and lack of eye contact. They are unwilling to use the word "no" even when they actually disagree with others.

These interpersonal behaviors are strongly influenced by Confucianism, which has been described as emphasizing hierarchical relationships, collectivism, obedience to authority, and emotional control (Lee \& Rong, 1988; Maker \& Schiever, 1989; Mizokawa \& Ryckman, 1988). The hierarchical relationship dictates that children must listen and not question the authority of their parents or teachers. The public expression of thoughts or strong feelings (e.g., pain, anger, love) is considered arrogant and defiant (Park, 1999).

In the school context, Korean American students often show passive and silent behaviors, which are due primarily to their early training from parents to respect and obey authority figures. As another example, teachers may notice that Korean American students don't speak loudly or disagree in a classroom. The reasons are that they may not be sure of the answers, they may want to avoid personal embarrassment when they are wrong, or they may fear that their answer may run contrary to the teacher's opinions (Park, 1999).

Strong kinship and extended (multigenerational) families are common among Korean Americans, in which collective or shared responsibility, group needs and cooperation, and patience are valued (Lee, 1989; Lee \& Rong, 1988; Maker \& Schiever, 1989; Mizokawa \& Ryckman, 1988). They prefer to work as a group in ways of collectivity, unity, and collaboration. Accordingly, a teacher can expect to notice a strong need for affiliation, social acceptance, and peers' approval among Korean American students.

Confucianism places great importance on education. Because Korean Americans place a high value on educational achievement and perceive education as the major avenue for upward mobility in a society (Ho, 1994; Lee \& Cynn, 1991; Pang, 1990, 1995; Park, 1998; Sue \& Okazaki, 1990), parents want and expect their children to have a good education and good grades in school (Caplan, Choy, \& Whitmore, 1992; Chan, 1986; Lee, 1989; Maker \& Schiever, 1989; Mizokawa \& Ryckman, 1988; Peng, Owing, \& Fetters, 1984; Sue, 1989; Yagi \& Oh, 1995). Specifically, parental expectations could be shown in the way parents socially compare their children with other students who are doing well in school. According to interviews of Pai and colleagues with Korean American students (Pai, Pemberton, \& Worley, 1987), 71\% of the youths reported school performance as their primary concern, $88 \%$ considered 
making their parents proud as quite important, and 90\% reported doing well in school.

Therefore, the purpose of this study is to explore the cultural orientation of Korean American students and to provide the educational implications for how teachers and administrators articulate, reflect on, and modify their attitudes and values with regard to cultural adaptation of Korean American students into the mainstream culture.

\section{Method}

\section{Participants}

The students were 466 Korean Americans (230 males, 234 females, and 2 did not specify) living in the New York City and Chicago areas. Students ranged in age from 10 to 19 years with a mean age of 14.97 years. With respect to grade level, there were 139 students (29.8\%) attending middle school and 327 students (70.2\%) attending high school. In terms of generation, there were $21(4.5 \%)$ Koreans, $31(6.7 \%)$ first generations, $130(27.9 \%)$ one and half generations, 244 $(52.4 \%)$ second generations, $29(6.2 \%)$ third generations, and 11 (2.3\%) did not specify. The generational statuses were categorized by the following descriptions:

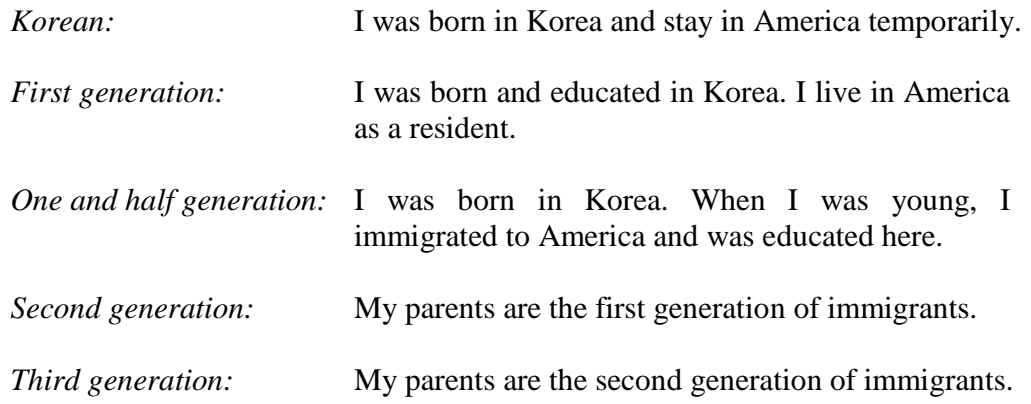

Sixty-one percent of students identified themselves as a Korean American; 23\% as a Korean. Fifty-eight percent reported they were born in America; 23\% of the students were between the ages of 0-11 years on arrival in America; and 19\% were more than 12 years on arrival. Ninety-two percent of students expected to receive higher education beyond a 4-year college degree. 


\section{Measurements}

A scale entitled the Korean American Acculturation Scale (KAAS, Lee, 2003) was developed to address cultural orientation characteristics and patterns of Korean Americans. Items were generated for an initial list for the $K A A S$ in the following three ways: (a) by reviewing the literature on the acculturation process; (b) by using two panel group meetings; and (c) by conducting a pilot study.

Four behavior dimensions of cultural orientation were identified as a result of a literature review process: language usage, food preference, friendship patterns, and cultural activities. The following 12 cultural value dimensions were identified: avoidance of family shame, collectivism, conformity to family and social norms, educational and occupational achievement, filial piety, importance of family, maintenance of interpersonal harmony, placing other's needs ahead of one's own, reciprocity, respect for elders and ancestors, selfcontrol and restraint, and self-effacement.

To reduce the overall number of dimensions and items generated by reviewing the literature on the acculturation process, a five-member panel of Korean students reviewed all of the statements that described Korean culture. From the standpoint of this panel group, two behavior dimensions and three cultural value dimensions were created and each dimension included three to seven items. Next, to identify whether the item content and the response format of the scale were appropriate, 20 content experts participated in a judgmental process. Six of these experts were university professors in educational psychology. The content expert package included 33 items based on works published about acculturation (Abe-Kim, Okazaki, \& Guto, 2001; Bosher, 1995; Cuéllar et al., 1995; Kim \& Abreu, 2001; Kim, Atkinson, \& Yang, 1999; Sodowsky et al., 1991; Suinn et al., 1995; Szapocznik et al, 1978). After experts' comments were reviewed, items were rewritten, deleted, and added. Finally, the pilot study for 20 Korean Americans (10 students and 10 parents) was administered to examine the appropriateness of items and response format.

The cultural behavior orientation (15 items) consisted of two dimensions: Usage $(\alpha$ reliability $=.92)$ and Social contact $(\alpha$ reliability $=.85)$. The cultural value orientation (18 items) included three dimensions: Collectivism $(\alpha$ reliability $=.78)$, Success $(\alpha$ reliability $=.77)$, and Self-control $(\alpha$ reliability $=.70)$. All response sets were based on a 5-point Likert-type scale ( $1=$ strongly disagree; $5=$ strongly agree). Every effort was made in developing the response sets to create equal intervals between choices, as equal-scale intervals were a necessary condition for applying statistical procedures to the data obtained. 


\section{Data Analysis}

Data were analyzed using the Multivariate Analysis of Covariance (MANCOVA) to assess the significance of independent variables on dependent variables. In this study, difference in age was a covariate. To investigate the impact of each main effect on the individual dependent variable, a RoyBargmann Stepdown analysis was performed on the prioritized dependent variables.

\section{Results}

\section{Cultural Behavior Orientation}

A $2 \times 5$ MANCOVA was performed on two dependent variables associated with cultural behavior orientation of respondents: Usage and Social contact. Respondent' age served as a covariate. The total number of 466 respondents was reduced to 433 when those with missing values were deleted. Observational means, standard deviations, and adjusted means for each group and dependent variables are presented in Table 1.

Pearson correlation analysis was performed to examine the relationship among the variables. There was a high correlation between two dependent variables, $r_{\text {Usage Social contact }}=.620$, which was a concern for multicollinearity. Age (covariate) was correlated with the two dependent variables, $r_{\text {Age Usage }}=.684, r$ Age Social contact $=.373$. Therefore, the age variable was expected to adjust for initial differences in Usage and Social contact as a covariate.

\section{Effects of Gender and Generation on Cultural Behavior Orientation}

The main effect for gender was not found, Wilks' $\Lambda=.99, F_{(2,421)}=1.89, p=$ .152 , effect size $=.009$. The main effect for generation was statistically significant, Wilks' $\Lambda=.69, F_{(8,842)}=21.06, p<.001$, effect size $=.167$. This means that about $16.7 \%$ of the generalized variance in the dependent variables was explained by generation after adjusting for the initial differences in age. The interaction term was not statistically significant, Wilks' $\Lambda=.99, F_{(8,842)}=.72, p$ $=.680$.

Because the omnibus MANCOVA showed significant main effect, this study further investigated the nature of the relationships among the independent variables and the dependent variables. Effects of generation on the dependent variables after adjustment for a covariate were investigated in Univariate and Roy-Bargmann Stepdown analyses, in which Usage was given the first priority and Social contact second priority (so that adjustment was made for Usage 
Journal of Praxis in Multicultural Education, Vol. 2, No. 1 [2010], Art. 3

Lee

Table 1

Observational Means, Standard Deviations, and Adjusted Means of Cultural Behavior Orientation

\begin{tabular}{|c|c|c|c|c|c|c|c|c|c|}
\hline \multirow{2}{*}{$\begin{array}{r}\text { Gender } \\
\text { Generation }\end{array}$} & \multirow[b]{2}{*}{$\begin{array}{c}\text { Cultural } \\
\text { Behavior } \\
\text { Orientation }\end{array}$} & \multicolumn{4}{|c|}{ Male } & \multicolumn{4}{|c|}{ Female } \\
\hline & & Mean & $\begin{array}{c}\text { Adjusted } \\
\text { Mean }\end{array}$ & $S D$ & $N$ & Mean & $\begin{array}{c}\text { Adjusted } \\
\text { Mean }\end{array}$ & $S D$ & $N$ \\
\hline \multirow[b]{2}{*}{ Korean } & Usage & 3.36 & 3.39 & 1.07 & 11 & 4.00 & 3.77 & .88 & 7 \\
\hline & $\begin{array}{c}\text { Social } \\
\text { Contact }\end{array}$ & 3.46 & 3.46 & 1.54 & & 4.18 & 3.97 & 1.10 & \\
\hline \multirow[b]{2}{*}{ First } & Usage & 3.08 & 3.09 & 1.14 & 14 & 2.99 & 3.00 & 1.17 & 17 \\
\hline & $\begin{array}{c}\text { Social } \\
\text { Contact }\end{array}$ & 3.91 & 3.92 & 1.05 & & 3.72 & 3.73 & 1.08 & \\
\hline \multirow{2}{*}{$\begin{array}{c}\text { One and } \\
\text { Half }\end{array}$} & Usage & 2.67 & 2.68 & 1.03 & 55 & 3.06 & 3.08 & 1.07 & 66 \\
\hline & $\begin{array}{c}\text { Social } \\
\text { Contact }\end{array}$ & 3.34 & 3.35 & 1.23 & & 3.96 & 3.98 & .95 & \\
\hline \multirow[b]{2}{*}{ Second } & Usage & 1.86 & 1.89 & .58 & 118 & 1.97 & 2.01 & .67 & 117 \\
\hline & $\begin{array}{c}\text { Social } \\
\text { Contact }\end{array}$ & 3.19 & 3.22 & 1.05 & & 3.53 & 3.56 & .95 & \\
\hline \multirow[b]{2}{*}{ Third } & Usage & 1.96 & 2.02 & .82 & 14 & 2.06 & 2.10 & .54 & 14 \\
\hline & $\begin{array}{c}\text { Social } \\
\text { Contact }\end{array}$ & 2.82 & 2.87 & 1.23 & & 3.04 & 3.00 & .92 & \\
\hline \multirow{2}{*}{ Total } & Usage & 2.34 & & .99 & 433 & & & & \\
\hline & $\begin{array}{c}\text { Social } \\
\text { Contact }\end{array}$ & 3.47 & & 1.09 & & & & & \\
\hline
\end{tabular}

Table 2

Effect Tests of Age and Generation on Cultural Behavior Orientation

\begin{tabular}{ccccccc}
\hline \multirow{2}{*}{ Effects } & DVs & Univariate $F$ & $d f$ & Stepdown $F$ & $d f$ & $\alpha$ \\
\hline Covariate & Usage & $5.48 *$ & $1 / 422$ & $5.48 *$ & $1 / 422$ & .025 \\
(Age) & Social Contact & 2.60 & $1 / 422$ & .22 & $1 / 421$ & .025 \\
\hline \multirow{2}{*}{ Generation } & Usage & $40.10^{\text {a }}$ & $4 / 422$ & $40.10 * *$ & $4 / 422$ & .025 \\
& Social Contact & $3.91^{\text {a }}$ & $4 / 422$ & $4.58 * *$ & $4 / 421$ & .025 \\
\hline Note. ${ }^{\text {a }}$ significant level cannot be evaluated but would reach at $p<.01$ in Univariate $F . *$ \\
$p<.05, * * p<.01$.
\end{tabular}


as well as for a covariate, age). Results of these analyses are summarized in Table 2. An experiment-wise error rate of $5 \%$ was achieved by the appointment of alpha as shown in the last column of Table 2 for each of the dependent variables.

After adjusting for differences on a covariate, Usage made a significant contribution to the composite of the dependent variables that best distinguishes differences among generations, Stepdown $F_{(4,422)}=40.10, p<$ .001 . The more recent generations showed less Usage after adjustment for their ages. The measure of Social contact, after adjusting for a covariate and Usage, was also related to differences in generations, Stepdown $F_{(4,421)}=4.58, p=$ .001. Univariate analysis for generation effect revealed that reliable difference was also presented on Social contact, $F_{(4,422)}=3.91, p=.004$, although the difference was already accounted for by age and Usage.

These significant main effects were followed by planned comparisons. There were significant differences between generations on Usage after adjusting for a covariate. The one and half generations (adjusted $M=2.88$ ) showed higher Usage than second generations (adjusted $M=1.95$ ), $t=10.03, p$ $<.001$. When comparing third generations (adjusted $M=2.06$ ) and the average of other generations (adjusted $M=2.86$ ) after controlling for their ages, there were significant differences in Usage, $t=4.70, p<.001$. However, there were no significant differences in Social contact with comparisons of two continuous generations (e.g., the one and half generation vs. second generation). In comparing third generations (adjusted $M=2.06$ ) and the average of other generations (adjusted $M=2.86$ ) after controlling for their ages, there were significant differences in Social contact, $t=3.11, p=.002$. This means that the more recent generations were more behaviorally disoriented from Korean culture. The degrees or modes of cultural disorientation for Usage and Social contact were different by generations of Korean American students. The cultural disorientation for Social contact with persons who have same cultural backgrounds seemed to be slower than that of Usage.

\section{Cultural Value Orientation}

A 2 x 5 MANCOVA was performed on the three dependent variables associated with cultural value orientation of respondents: Collectivism, Success, and Self-control. Adjustment was made for respondent's age. The number of 466 respondents was reduced into 429, a loss of $8 \%$ due to missing data. Observational means, standard deviations, and adjusted means for each group and dependent variables are presented in Table 3 .

Pearson correlation analysis was conducted to examine the 
relationship among the variables. There were high correlations between two dependent variables, $r$ collectivism Success $=.384, r$ Collectivism Self-control $=.426$, and $r$ Success Self-control $=.273$, which was a concern for multicollinearity. Age (covariate) was correlated with the dependent variables, $r$ Age Collectivism $=.320, \quad r$ Age Success $=-$ .098 , and $r$ Age self-control $=.227$. Therefore, the age variable was expected to adjust for initial differences in Collectivism, Success, and Self-control.

Table 3

Observational Means, Standard Deviations, and Adjusted Means of Cultural Value Orientation

\begin{tabular}{|c|c|c|c|c|c|c|c|c|c|}
\hline \multirow{2}{*}{$\begin{array}{r}\text { Gender } \\
\text { Generation }\end{array}$} & \multirow[b]{2}{*}{$\begin{array}{c}\text { Cultural Value } \\
\text { Orientation }\end{array}$} & \multicolumn{4}{|c|}{ Male } & \multicolumn{4}{|c|}{ Female } \\
\hline & & Mean & $\begin{array}{l}\text { Adjusted } \\
\text { Mean }\end{array}$ & SD & $\mathrm{N}$ & Mean & $\begin{array}{l}\text { Adjusted } \\
\text { Mean }\end{array}$ & SD & $\mathrm{N}$ \\
\hline \multirow{3}{*}{ Korean } & Collectivism & 3.75 & 3.76 & 1.07 & 11 & 3.62 & 3.53 & .81 & 7 \\
\hline & Success & 3.18 & 3.17 & 1.35 & & 3.10 & 3.24 & 1.13 & \\
\hline & Self-control & 3.75 & 3.74 & .71 & & 3.87 & 3.99 & .54 & \\
\hline \multirow{3}{*}{ First } & Collectivism & 3.80 & 3.80 & .69 & 14 & 3.42 & 3.42 & .65 & 17 \\
\hline & Success & 3.41 & 3.40 & 1.06 & & 3.31 & 3.31 & 1.16 & \\
\hline & Self-control & 3.70 & 3.69 & .76 & & 3.64 & 3.63 & .60 & \\
\hline \multirow{3}{*}{$\begin{array}{l}\text { One and } \\
\text { Half }\end{array}$} & Collectivism & 3.61 & 3.62 & .60 & 53 & 3.48 & 3.49 & .62 & 66 \\
\hline & Success & 3.31 & 3.31 & .86 & & 3.15 & 3.13 & .87 & \\
\hline & Self-control & 3.81 & 3.80 & .60 & & 3.89 & 3.88 & .58 & \\
\hline \multirow{3}{*}{ Second } & Collectivism & 3.39 & 3.41 & .69 & 118 & 3.18 & 3.20 & .58 & 116 \\
\hline & Success & 3.33 & 3.31 & .95 & & 3.00 & 2.98 & .91 & \\
\hline & Self-control & 3.87 & 3.86 & .67 & & 3.70 & 3.68 & .62 & \\
\hline \multirow{3}{*}{ Third } & Collectivism & 3.56 & 3.59 & 1.05 & 13 & 3.20 & 3.22 & .61 & 14 \\
\hline & Success & 3.13 & 3.09 & 1.01 & & 3.29 & 3.26 & 1.25 & \\
\hline & Self-control & 3.65 & 3.62 & 1.08 & & 3.57 & 3.55 & .76 & \\
\hline \multirow{3}{*}{ Total } & Collectivism & 3.40 & & .68 & 429 & & & & \\
\hline & Success & 3.20 & & .96 & & & & & \\
\hline & Self-control & 3.79 & & .65 & & & & & \\
\hline
\end{tabular}

\section{Effects of Gender and Generation on Cultural Value Orientation}

A main effect for gender was found, Wilks' $\Lambda=.98, F_{(3,416)}=$ 2.82, $p=.039$, effect size $=.020$. This means that $2.0 \%$ of the generalized variance in the dependent variables was explained by 
gender. The main effect for generation was statistically significant, Wilks' $\Lambda=.95, F_{(12,1100)}=2.02, p=.020$, effect size $=.019$. This means that about $1.9 \%$ of the generalized variance in the dependent variables was explained by generation after adjusting for the initial differences in age. The interaction term was not statistically significant, Wilks' $\Lambda=$ $.98, F_{(12,1100)}=.77, p=.687$.

Effects of gender and generation on the dependent variables after adjustment for a covariate were investigated in Univariate and Roy-Bargmann Stepdown analyses, in which Collectivism was given the highest priority, Success was given second priority (so that adjustment was made for a covariate and Collectivism), and Self-control was third priority (so that adjustment was made for Collectivism and Success, as well as a covariate). Results of these analyses are summarized in Table 4.

Table 4

Effect Tests of Generation on Cultural Value Orientation

\begin{tabular}{ccccccc}
\hline Effects & DVs & Univariate $F$ & $d f$ & Stepdown $F$ & $d f$ & $\alpha$ \\
\hline \multirow{2}{*}{ Covariate } & Collectivism & 1.29 & $1 / 418$ & 1.29 & $1 / 418$ & .016 \\
(Age) & Success & 1.52 & $1 / 418$ & 4.02 & $1 / 417$ & .016 \\
& Self-control & 2.40 & $1 / 418$ & 3.22 & $1 / 416$ & .016 \\
\hline \multirow{3}{*}{ Gender } & Collectivism & $6.73^{* *}$ & $1 / 418$ & $6.73^{* *}$ & $1 / 418$ & .016 \\
& Success & .24 & $1 / 418$ & .68 & $1 / 417$ & .016 \\
& Self-control & .01 & $1 / 418$ & 1.03 & $1 / 416$ & .016 \\
\hline \multirow{3}{*}{ Generation } & Collectivism & $4.02^{\text {a }}$ & $4 / 418$ & $4.02^{\text {a }}$ & $4 / 418$ & .016 \\
& Success & .40 & $4 / 418$ & .34 & $4 / 417$ & .016 \\
& Self-control & 1.13 & $4 / 418$ & 1.75 & $4 / 416$ & .016 \\
\hline
\end{tabular}

Note. ${ }^{\text {a }}$ significant level cannot be evaluated but would reach at $p<.01$ in Univariate $F$. $* p<.05, * * p<.01$.

After adjusting for differences on a covariate, Collectivism made a significant contribution to the composite of the dependent variables that best distinguishes differences between male and female Korean American students, Stepdown $F_{(1,418)}=6.73, p=.010$. Male Korean American students showed greater Collectivism after adjusting for their ages than female students. But, Stepdown and Univariate analysis for gender effect show that reliable differences were not presented on the other two cultural values, Success and 
Self-control.

Generation differed in Collectivism, the first priority dependent variable, after adjustment for a covariate, Stepdown $F_{(4,418)}=4.02, p=.003$. But, the measures of Success and Self-control, after adjusting for a covariate and the priority variable(s), were not related to differences in generations, Stepdown $F_{(4,417)}=.34, p=.851$ and Stepdown $F_{(4,416)}=1.75, p=.137$.

These significant main effects were followed by planned comparisons. There was significant difference between males and females on Collectivism after adjusting for age. Male Korean American students (adjusted $M=3.64$ ) showed higher Collectivism than female Korean American students (adjusted $M=3.37$ ), $t=2.59, p=.009$. Male students, then, were characterized by slower cultural value disorientation than females, when adjustment was made for their ages.

There was a significant difference between one and half generations and second generations on Collectivism, after adjusting for a covariate. The one and half generations (adjusted $M=3.56$ ) showed higher Collectivism tendency than the second generations (adjusted $M=3.31$ ), $t=3.33, p<.001$. Even though the younger generation had less Success and Self-control than the older generation, differences of generations in Success and Self-control were not found, after controlling for age. This means that Korean American students seemed to be selectively disoriented from their cultural value. As Korean American students interact with the mainstream culture, they seemed to gradually disorient from Collectivism cultural value, while maintaining Success and Self-control value.

\section{Discussion}

\section{Cultural Behavior Orientation}

After adjusting for participants' ages, statistically significant differences in cultural behavior orientation, Usage, and Social contact among generations were found. Since later generations (i.e., second or third) were behaviorally more disoriented from their culture, they seemed to use and involve themselves in Korean things, such as Korean language, social customs, and food preference, less, which might exemplify the overall process of cultural adaptation to the mainstream behaviors.

The generation differences between one and half generations and second generations were especially interesting. Known as the transgeneration or knee-high generation, one and half generations consist of bicultural and bilingual Korean Americans who are foreign born, but have spent the majority of their developmental years in the United States (Lee \& Cynn, 1991; Yu, 1988). 
These bicultural features of one and half generations may assist them in expanding their repertoires of behaviors.

Biculturalism can encourage new behavior coping strategies that meet the demands of a given time, place, and situation. For example, when the one and half generation individual is at home with an elderly family member, he or she may be exposed to more Korean food, holidays, language, or T.V. and may interact with Korean styles. In a school setting, however, he or she may be more exposed to the mainstream culture and may interact with the mainstream styles.

To use new behavior coping strategies appropriately in a given time, place, and situation may be confusing for many one and half generation Korean Americans. Because they cannot communicate effectively with their parents who usually are first generation or their friends due to their primary language (Korean), one and half generation Korean Americans often feel alienated. According to the results from this study, the type and degree of behavior and cultural value orientation found in one and half generations, which are distinguished from first and/or second generations, show characteristics of this generation's transition point. It is necessary to consider the experiences of one and half generations separately from those of first and second generations in terms of bilingual education and counseling.

\section{Cultural Value Orientation}

There was a significant difference in cultural value orientation (Collectivism) between male and female Korean American students, after adjusting for participants' ages. Male students showed higher Collectivism cultural value orientation than female students. Male students were characterized by a slower cultural value change rate into the mainstream culture than female students, when adjustments were made for their ages. That is, male Korean American students were more likely to show the tendency of conforming to the family and social norms. They would consider their cultural value toward society and family before themselves.

The gender differences in cultural value orientation were supported by research (Brandon, 1991; Fong, 1973; Sodowsky \& Plake, in press; Tang \& Dion, 1999). Males adapted less easily to some aspects of the mainstream culture than females. The possible interpretation is that males generally succeed to their family tree in Korea. So, traditional Korean culture defines different roles and expectations for males and females (Lee, 1989; Lee \& Rong, 1988; Maker \& Schiever, 1989; Mizokawa \& Ryckman, 1988), which could be reflected in gender differences in Collectivism cultural value.

After adjusting for a covariate, generation differed in Collectivism. The one and half generations showed higher Collectivism tendency than second generations. The differences among generations in Success and Self-control 
cultural value were not found after controlling for age, even though the younger generation had less Success and Self-control cultural value than the older generation.

There were a number of possible reasons for these results. Statistically, because of the high correlations between the covariate and the dependent variables, variances explained by Success and Self-control could be explained by a covariate (age). Second, since the mainstream society expects individualism, defiance of authority, and independence for Korean Americans, Collectivism might be compelled to change more than other cultural values. Third, unlike Collectivism, Success and Self-control have educational and economic survival values that produce positive outcomes within the mainstream society and there is no compelling reason to change them to fit the mainstream group's values.

\section{Implications and Limitations of Korean Americans' Cultural Orientation Study}

This study demonstrates that Korean American students make conscious choices about what to adopt from the mainstream culture, particularly in terms of food preference, language, and social activity, as well as what to maintain from their Korean cultural values, particularly in terms of Success and Self-control. Moreover, this finding supports the research that cultural value disorientation occurs more slowly than cultural behavior disorientation among culturally diverse groups (Szapocznik \& Kurtines, 1980; Szapocznik et al., 1978). The different disorientation rates in behaviors and cultural values could result in misunderstanding of persons by the mainstream culture. For example, Korean American students show their acculturated or Americanized behaviors outwardly but still have their ethnic cultural value inwardly, which might not fit well with values inherent in conventional teaching or counseling strategies. Even teachers who have the cultural differences perspective for Korean American students often require Korean American students to fit into the mainstream culture. These teachers may not modify the learning environment to support Korean Americans' cultural differences because they do not recognize the difference between internal and external cultural orientation responses. Teachers could expect Korean American students to be independent, competitive, or express their thoughts and opinions in public, while Korean American students could be more comfortable in direct instruction or cooperative learning situations and might not do well in competitive environments.

Some limitations exist with respect to the survey instruments. One of these issues is the overgeneralization of the operational definitions of the KAAS, which was used to describe cultural orientation characteristics. As items of the 
$K A A S$ represented Korean-oriented behaviors and cultural values, Korean Americans rated highly on items would be perceived as having behaviors and cultural values oriented toward Korean. But, Korean Americans rated lowly on items would not be perceived as having behaviors and cultural values oriented toward Other-group, the American group. In other words, a high score indicates valuing Korean culture but a low score does not mean valuing American culture.

This study sampled participants conveniently rather than randomly in the Korean American Churches in the New York City and Chicago areas. Data were collected from participants who were accessible and cooperative. Because participants attending the Korean American Churches in the New York City and Chicago areas have more contacts with their ethnic groups, this might result in higher scores in Korean orientation or Korean language index than one would find with Koreans in other areas. The generalizability of these results is limited to Korean Americans attending these churches in the metropolitan city who responded to this study.

Bias in self-reporting might have been shown in the scales to decrease validity of responses by participants. Social desirability bias, participant reactance, and participant perception of threat by items in scales might influence bias in self-reporting. In particular, social desirability, which is the tendency of individuals to deny socially undesirable actions and behaviors and to admit to socially desirable ones, would affect responses in a manner so that participants would report higher frequencies of action considered desirable by their cultural standards and norms.

\section{References}

Abe-Kim, J., Okazaki, S., \& Guto, S. G. (2001). Unidimensional versus multidimensional approaches to the assessment of acculturation for Asian American populations. Cultural Diversity and Ethnic Minority Psychology, 7, 232-246.

Banks, J. A. (1993). Multicultural education: Development dimensions and challenges. Phi Delta Kappan, 75, 22-28.

Betancourt, H., \& Lopez, S. R. (1993). The study of culture, ethnicity, and race in American psychology. American Psychologist, 48, 627-637.

Bosher, S. D. (1995). Acculturation, ethnicity, and second language acquisition: A study of Hmong students at the post-secondary level. Unpublished doctoral dissertation, University of Minnesota, Minneapolis.

Brandon, P. R. (1991). Gender differences in young Asian Americans' educational attainments. Sex Roles, 25, 45-61.

Caplan, N., Choy, M. H., \& Whitmore, J. K. (1992). Indochinese refugee families and academic achievement. Scientific American, 266, 36-42.

Chan, K. S. (1986). Parents of exceptional Asian children. In M. K. Kitano \& P. C. Chinn (Eds.), Exceptional Asian children and youth (pp. 36-53). Reston, VA: The Council for Exceptional Children. 
Cheng, L. L., Ima, K., \& Labovitz, G. (1994). Assessment of Asian and Pacific Islander students for gifted programs. In S. B. García (Ed.), Addressing cultural and linguistic diversity in special education (pp. 30-45). Reston, VA: The Council for Exceptional Children.

Cuéllar, I., Arnold, B., \& Maldonado, R. (1995). Acculturation Rating Scale for Mexican American-II: A revision of the original ARSMA scale. Hispanic Journal of Behavioral Sciences, 17, 275-301.

Dasgupta, S. S. (1989). On the trail of an uncertain dream. New York: AMS Press.

Fong, S. L. (1973). Assimilation and changing social roles of Chinese Americans. Journal of Social Issues, 29, 115-127.

Ford, D. Y., Howard, T. C., Harris, J. J., \& Tyson, C. A. (2000). Creating culturally responsive classrooms for gifted minority students. Journal for the Education of the Gifted, 23, 397-427.

Garcia, M., \& Lega, L. I. (1979). Development of a Cuban ethnic identity questionnaire. Hispanic Journal of Behavioral Sciences, 1, 247-261.

Ho, D. Y. F. (1994). Cognitive socialization in Confucian heritage cultures. In P. M. Greenfield \& R. R. Cocking (Eds.), Cross-cultural roots of minority child development (pp. 285-313). Hillsdale, NJ: Lawrence Erlbaum Associates.

Kim, B., \& Abreu, J. (2001). Acculturation measurement: Theory, current instruments, and future directions. In J. G. Ponterotto, J. M. Casas, L. A. Suzuki, \& C. M. Alexander (Eds.), Handbook of multicultural counseling ( $2^{\text {nd }}$ ed., pp. 394-424). Thousand Oaks, CA: Sage.

Kim, B. S., Atkinson, D. R., \& Yang, P. H. (1999). The Asian Values Scale: Development, factor analysis, validation, and reliability. Journal of Counseling Psychology, 46, 342-352.

LaFromboise, T., Coleman, H. L. K., \& Gerton, J. (1993). Psychological impact of biculturalism: Evidence and theory. Psychological Bulletin, 114, 395-412.

Lee, A. (1989). A socio-cultural framework for the assessment of Chinese children with special needs. Topics in Language Disorders, 9, 38-44.

Lee, J. C., \& Cynn, V. E. H. (1991). Issues in counseling 1.5 generation Korean Americans. In C. C. Lee \& B. L. Richardson (Eds.), Multicultural issues in counseling: New approaches to diversity (pp. 127-140). Alexandria, VA: American Association for Counseling and Development.

Lee, E. S., \& Rong, X. (1988). The educational and economic achievement of AsianAmericans. The Elementary School Journal, 88, 545-560.

Lee, M-S. (2003). Korean American Acculturation Scale (KAAS). Unpublished scale. Storrs, CT: University of Connecticut.

Leong, F. T. L., Wagner, N. S., \& Tata, S. P. (1995). Racial and ethnic variations in help seeking attitudes. In J. G. Ponterotto, J. M. Casas, L. A. Suzuki, \& C. M. Alexander (Eds.), Handbook of multicultural counseling (pp. 415-438). Thousand Oaks, CA: Sage.

Lynch, E. W., \& Hanson, M. J. (Eds.). (1998). Developing cross-cultural competence (2 ${ }^{\text {nd }}$ ed.). Baltimore: Paul H. Brookes.

Maker, C. J., \& Schiever, S. W. (1989). Asian-Americans. In C. J. Maker \& S. W. Schiever (Eds.), Critical issues in gifted education: Defensible programs for cultural and ethnic minorities (Vol. 2, pp. 149-153). Austin, TX: PRO-ED. 
Marin, G., Sabogal, F., Marin, B. V., Otero-Sabogal, R., \& Perez-Stable, E. (1987). Development of a short acculturation scale for Hispanics. Hispanic Journal of Behavioral Sciences, 9, 183-205.

Mau, R. Y. (1998). Using various assessment methods in culturally responsive education for Asian and Pacific American students. In R. Endo, C. C. Park, \& J. N. Tsuchida (Eds.), Current issues in Asian and Pacific American education (pp. 23-35). South El Monte, CA: Pacific Asia Press.

Mercer, J. R. (1976). Pluralistic diagnosis in the evaluation of Black and Chicano children: A procedure for taking sociocultural variables into account in clinical assessment. In C. A. Hernández, M. J. Haug, \& N. N. Wagner (Eds.), Chicanos: Social and psychological perspectives ( $2^{\text {nd }}$ ed., pp.183-195). St. Louis: Mosby.

Mizokawa, D. T., \& Ryckman, D. B. (1988, April). Attributions of academic success and failure to effort or ability: A comparison of six Asian American ethnic groups. Paper presented at the annual meeting of the American Educational Research Association, New Orleans. (ERIC Document No. ED293960)

Nguyen, L., \& Peterson, C. (1993). Depressive symptoms among Vietnamese American college students. Journal of Social Psychology, 133, 65-71.

Nguyen, L., \& Williams, H. L. (1989). Transition from East to West: Vietnamese adolescents and their parents. American Academy of Child and Adolescent Psychiatry, 28, 505-515.

Padilla, A. M. (1980). The role of cultural awareness and ethnic loyalty in acculturation. In A. M. Padilla (Ed.), Acculturation: Theory, models, and some new findings (pp. 47-84). Boulder, CO: Westview Press.

Padilla, A. M., Lindholm, K. J., \& Wagatsuma, Y. (1985). Acculturation and personality as predictors of stress in Japanese and Japanese-Americans. Journal of Social Psychology, 125, 295-305.

Pai, Y., Pemberton, D., \& Worley, J. (1987). Findings on Korean American early adolescents and adolescents. Kansas City, MO: School of Education, University of Missouri-Kansas City.

Pang, V. O. (1990). Asian-American children: A diverse population. Educational Forum, $55,49-66$.

Pang, V. O. (1995). Asian American children: A diverse population. In D. T. Nakanishi \& T. Y. Nishida (Eds.), The Asian American educational experience: A source book for teachers and students (pp. 167-179). NY: Routledge.

Park, C. C. (1998). Educational and occupational aspirations of Korean youth in Los Angeles. In R. Endo, C. C. Park, \& J. N. Tsuchida (Eds.), Current issues in Asian and Pacific American education (pp. 65-76). West Covina, CA: Pacific Asia Press.

Park, C. C. (1999). Schooling for Korean-American students: A sociocultural perspective. In C. C. Park \& M. M. Chi (Eds.), Asian American education: Prospects and challenges (pp. 47-70). Westport, CT: Bergin \& Garvey.

Park, C. C., \& Chi, M. M. (1999). Asian American education: Prospects and challenges. Westport, CT: Bergin \& Garvey.

Peng, S. S., Owing, J. A., \& Fetters, W. B. (1984). School experiences and performance of Asian-American high school students. In J. Wang (Ed.), Entering the 
mainstream: A report of the East Coast Asian American Education Conference (pp. 15-16). Washington, DC. (ERIC Document No. ED253607)

Shade, B. J., Kelly, C., \& Oberg, M. (1997). Creating culturally responsive classrooms. Washington, DC: American Psychological Association

Sodowsky, G. R., \& Carey, J. C. (1988). Relationships between acculturation-related demographics and cultural attitudes of an Asian Indian immigrant group. Journal of Multicultural Counseling and Development, 16, 117-135.

Sodowsky, G. R., Kwan, K. K., \& Pannu, R. (1995). Ethnic identity of Asians in the United States. In J. G. Ponterotto, J. M. Casas, L. A. Suzuki, \& C. M. Alexander (Eds.), Handbook of multicultural counseling (pp. 123-154). Thousand Oaks, CA: Sage.

Sodowsky, G. R., Lai, E. W. M., \& Plake, B. S. (1991). Moderating effects of sociocultural variables on acculturation attitudes of Hispanics and Asian Americans. Journal of Counseling and Development, 70, 194-204.

Sodowsky, G. R., \& Plake, B. S. (1991). Psychometric properties of the AmericanInternational Relations Scale. Educational and Psychological Measurement, 51, 207-216.

Sodowsky, G. R., \& Plake, B. S. (in press). Acculturation options of international people and implications for sensitivity to within group differences. Journal of Counseling and Development.

Sue, D. W. (1989). Ethnic identity: The impact of two cultures on the psychological development of Asians in America. In D. R. Atkinson, G. Morten, \& D. W. Sue (Eds.), Counseling American minorities: A cross-cultural perspective $\left(3^{\text {rd }}\right.$ ed., pp. 103-115). Dubuque, IA: William C. Brown.

Sue, S., \& Okazaki, S. (1990). Asian American educational achievements: A phenomenon in search of an explanation. American Psychologist, 45, 913-920.

Suinn, R. M., Khoo, G., \& Ahuna, C. (1995). The Suinn-Lew Asian Self-Identity Acculturation Scale: Cross-cultural information. Journal of Multicultural Counseling and Development, 23, 139-148.

Szapocznik, J., \& Kurtines, W. (1980). Acculturation, biculturalism, and adjustment among Cuban Americans. In A. M. Padilla (Ed.), Acculturation: Theory, models, and some new findings (pp. 139-159). Boulder, CO: Westview Press.

Szapocznik, J., Kurtines, W., \& Fernandez, T. (1980). Bicultural involvement and adjustment in Hispanic American youths. International Journal of Intercultural Relations, 4, 353-365.

Szapocznik, J., Scopetta, M. A., Kurtines, W., \& Arandale, M. A. (1978). Theory and measurement of acculturation. Interamerican Journal of Psychology, 12, 113130.

Tang, T. N., \& Dion, K. L. (1999). Gender and acculturation in relation to traditionalism: Perceptions of self and parents among Chinese students. Sex Roles, 41, 17-29.

Tsai, J. L., Ying, Y. W., \& Lee, P. A. (2000). The meaning of "being Chinese" and "being American": Variation among Chinese American young adults. Journal of Cross-Cultural Psychology, 31, 302-332.

VanTassel-Baska, J., Olszewski-Kubilius, P., \& Kulieke, M. (1994). A study of selfconcept and social support in advantaged and disadvantaged seventh and eighth grade gifted students. Roeper Review, 16, 186-191. 
Yagi, D. T., \& Oh, M. Y. (1995). Counseling Asian American students. In C. C. Lee (Ed.), Counseling for diversity: A guide for school counselors and related professionals (pp. 61-83). Boston, MA: Allyn \& Bacon.

Yu, E. Y. (1988, December). Critical issues of the Korean community in the future: Paper presented at the meeting of the United Way, Metropolitan Region, Los Angeles, CA. 